\title{
An Application of Bilevel Programming Problem in Optimal Pollution Emission Price
}

\author{
Guang-Min Wang ${ }^{1,2}$, Lin-Mao Ma ${ }^{1}$, Lan-Lan $\mathrm{Li}^{1}$ \\ ${ }^{1}$ School of Economics and Management, China University of Geosciences, Wuhan, China; ${ }^{2}$ Hubei Province Key Laboratory of \\ Systems Science in Metallurgical Process, Wuhan University of Science and Technology, Wuhan, China. \\ Email: wgm97@163.com
}

Received February 25 ${ }^{\text {th }}, 2011$; revised April 6 ${ }^{\text {th }}, 2011$; accepted April 24 ${ }^{\text {th }}, 2011$.

\begin{abstract}
Charging for the pollution is one of the ways to enhance the environmental quality. The appropriate price of the pollution emission is the most important question of the research on how to charge for the pollution. So, by constructing a bilevel programming model, we provide a novel way for solving the problem of charging for the pollution. In our model, the government (or the social regulation) chooses the optimal price of the pollution emission with consideration to firms' response to the price. And the firms choose their optimal quantities of the production to maximize their profits at the given price of the pollution emission. Finally, a simple example is illustrated to demonstrate the feasibility of the proposed model.
\end{abstract}

Keywords: Bilevel Programming, Pollution Emission, Price Control Problem

\section{Introduction}

Rapid economic development and population growth in China have left a legacy of widespread environmental pollution in the last two decades [1,2]. So, the research on environmental pollution is very important to enhance the environmental quality $[3,4]$. Now, three basic ways, such as regulation, Pigovian tax and transaction of emission permits, were used to abate the environmental pollution in developed countries. Because the firms' marginal costs are less than the social marginal cost, the firms will emit excess pollution, which shows that the firms will have negative externality to the environmental quality. For effectively dealing with the externality, which can not be solved by the market, the government regulation is adopted by prescribing the maximal quantity of the pollution emission, which is an administrative meaning to abate the environmental pollution. While the asymmetry information makes it hard to reach the ideal goal. So, Pigovian tax is adopted by imposing tax on the pollution to make the externality cost internal and give the firms an incentive to decrease the quantities of the pollution emission, which is an economic meaning to abate the environmental pollution. Based on the idea of making the environmental externality cost internal, transaction of emission permits corrects the distortion of the market's price resulted from the exposure of Pigovian tax to effectively abate the environmental pollution by use of definition of initial emission rights and the allocation market of initial emission rights as well as the trading market of emission rights. Now, China is experiencing an unprecedented discharge of pollutants within a relatively short time compared with developed nations, in which discharges were spread over a century or more $[1,5]$. Thus, the research on how to charge for pollution is one of the most important work to enhance the environmental quality. Among various factors, the price of the emission permits must be the first place, because it influences not only the environmental quality but also the allocation of natural resources and supply and demand of commodity. Thus, the scientific and reasonable price is the key to perform system of charging for pollution successfully [6].

Many authors have attempted to use techniques in the pollution abatement problem [7,8]. Additionally, a serious shortcoming of these optimization models is that complete information on the production and damage cost functions of every firm is assumed to be known. Although, each firm may know its own production cost functions, there is no reason to believe that this information will be readily available to the central authority [9]. Furthermore, Amouzegar and Jacobsen have conceptualized the problem in terms of a multilevel frame work [10]. 
Later, Amouzegar and Moshirvaziri presented two optimization models for hazardous waste capacity planning and treatment facility locations by investigating the complex behavior of firms in the presence of central planning decisions and price signals which can best be captured by a bilevel programming model [9].

In this paper, we propose a bilevel programming model different from the above bilevel models to abate the environmental pollution, in which the government(or the social government) chooses the price of the pollution emission to maximize the social profits by considering the firms' response to the price, and then the firms maximize their profits by choosing the optimal quantity of the production at the given price. Our model aims to discuss not only the scientific and reasonable price of the pollution emission to maximize the social profits but also the firms' choosing the optimal quantity of the production at the given price to maximize their profits. The remaining of the paper is organized as follows: Section 2 presents a bilevel programming model to determine the price of emission permits; Section 3 gives the algorithm for this bilevel programming model; a computational example is presented in Section 4 to demonstrate the feasibility of the model; finally, a conclusion and future work are given in Section 5.

\section{The Bilevel Programming Model}

If the government (or the social regulation) chooses the price $p$ of the pollution emission, then each firm will be in response to the price, and then, the government will adjust repeatedly the price according to the response of the firms until the government obtains the optimal price of pollution emission to maximize the social profits while each firm gain its maximizing profit at the given price. It can be seen that this process is the decision problem with hierarchical structure and the bilevel programming problem is a useful tool to solve this kind of problem [11].

Next, we will give some assumption before constructing the model. Supposing that there are $n$ firms to produce different productions and emit the same pollution. For simplicity, each firm only produces one kind of production. And the quantity of the pollution is only determined by the quantity of the production. Then, the charge of the per unit pollution emission is the same for different firms, and let $p$ denote the charge of the per unit pollution emission.

Thus, the $i t h(i=1,2, \cdots, n)$ firm chooses its quantity of production $p_{i}$ with the price $q_{i}$ of the production to maximize its profit $F_{i}\left(p, q_{i}\right)$ as the price of pollution emission is set by the government. And let the quantity of the pollution be the function of the quantity of production $q_{i}$, that is, the quantity of the pollution is $g_{i}\left(q_{i}\right)$.
Additionally, the $i$ firm's cost function is $c_{i}\left(q_{i}\right)$. Thus, the ith firm's profit function is:

$F_{i}\left(p, q_{i}\right)=p_{i} q_{i}-p g_{i}\left(q_{i}\right)-c_{i}\left(q_{i}\right)$. So, the ith firm aims to maximize its profit, that is,

$$
\max _{q_{i}} F_{i}\left(p, q_{i}\right)=p_{i} q_{i}-p g_{i}\left(q_{i}\right)-c_{i}\left(q_{i}\right) .
$$

where $p_{i}$ is the price of the production manufactured by the ith firm, and $p_{i}$ is fixed because the firms are all the price acceptors in the competitive market.

Thus, at the given price $p$ of the pollution emission, the total of the pollution is $q=\sum_{i=1}^{n} g_{i}\left(q_{i}\right)$. Obviously, the marginal cost of abating the pollution is decreasing as the quantity of the pollution, that is, abating pollution is economy of scale. Thus, we consider the situation that the pollutions are all abated by the government. $\mathrm{Hu}$ Zhenpeng et al. [12] determined the optimal price $p$ by minimizing the cost of abating the pollution, namely, the government (or the social regulation) chooses $p$ to minimize his objective function formulated as follows:

$$
\min _{p} C\left(\sum_{i=1}^{n} g_{i}\left(q_{i}\right)\right) .
$$

where $C(\bullet)$, which is the increasing function, is the cost function of abating the pollution. However, only to consider minimizing the cost of abating the pollution is not complete, because the pollution is the logical result of manufacturing the production for better our lives. Thus, we should consider maximizing the social profits at the same time consider minimizing the cost of abating the pollution. Hence, we treat the cost of abating the pollution as the cost of manufacturing social production. So, the government's objective function is formulated as follows:

$$
\begin{aligned}
F(p, q)= & \sum_{i=1}^{n}\left(p_{i} q_{i}-c_{i}\left(q_{i}\right)\right)+p\left(\sum_{i=1}^{n} g_{i}\left(q_{i}\right)\right) \\
& -C\left(\sum_{i=1}^{n} g_{i}\left(q_{i}\right)\right)
\end{aligned}
$$

where $C(\bullet)$, which is the increasing function, is the cost function of abating the pollution. Thus, the government aims to maximize his objective function formulated as follows:

$$
\begin{aligned}
\max _{p} F(p, q)= & \sum_{i=1}^{n}\left(p_{i} q_{i}-c_{i}\left(q_{i}\right)\right)+p\left(\sum_{i=1}^{n} g_{i}\left(q_{i}\right)\right) \\
& -C\left(\sum_{i=1}^{n} g_{i}\left(q_{i}\right)\right)
\end{aligned}
$$

Hence, we can propose the programming model formulated as follows: 


$$
\begin{aligned}
\max _{p} F(p, q)= & \sum_{i=1}^{n}\left(p_{i} q_{i}-c_{i}\left(q_{i}\right)\right)+p\left(\sum_{i=1}^{n} g_{i}\left(q_{i}\right)\right) \\
& -C\left(\sum_{i=1}^{n} g_{i}\left(q_{i}\right)\right) .
\end{aligned}
$$

where $q_{i}$ solves the following problem

$$
\max _{q_{i}} F_{i}\left(p, q_{i}\right)=p_{i} q_{i}-p g_{i}\left(q_{i}\right)-c_{i}\left(q_{i}\right) \text {. }
$$

where $i=1,2, \cdots, n$. Obviously, the model is a bilevel programming problem. Next, we will discuss the algorithm for this model.

\section{The Proposed Algorithm for the Model}

Although Bracken and McGill [13] gave the original formulation for bilevel programming in 1973, the problem started receiving the attention motivated by the game theory [14] till the early eighties. And many authors studied bilevel programming intensively and contributed themselves into those fields [15-18]. However, the bilevel programming is neither continuous anywhere nor convex even if the objective functions of the upper level and lower level and the constraints are all linear because the objective function of the upper level, which, generally speaking, is neither linear nor differentiable, is decided by the solution function of the lower level problem. Bard proved that the bilevel linear programming is a NP-Hard problem [19] and even it is a NP-Hard problem to search for the locally optimal solution of the bilevel linear programming [20]. So, it is greatly difficult to solve the bilevel programming for its non-convexity and non-continuity. When $n=1$, the problem (5) is similar with the price control problem, which has been researched by some authors with hypothesis that there only one solution to the lower level programming for fixed the upper level decision variable [21-24]. Recently, Yibing Lv et al. discussed a class of weak price control problems with nonunique lower level solutions and study the existence of solution via a penalty method [25]. In this paper, we discuss the situation that there are $n(\geq 2)$ firms based on above references.

After the government chooses the price $p$ of the pollution mission, the firms choose their quantity of the production to maximize their profits, and the optimal quantity of production is determined by the following equation:

$$
0=\frac{\partial F_{i}}{\partial q_{i}}=p_{i}-p \frac{\partial g_{i}}{\partial q_{i}}-\frac{\partial c_{i}}{\partial q_{i}}
$$

where $i=1,2, \cdots, n$. From the Equation (6), we can see that the ith firm's optimal quantity of production is determined by not only the firm's cost function $c_{i}\left(q_{i}\right)$ and polluting function $g_{i}\left(q_{i}\right)$ but also the price $p$ of the pollution emission. In fact, it is the function of the price $p$ of the pollution emission because the ith firm's cost function $c_{i}\left(q_{i}\right)$ and polluting function $g_{i}\left(q_{i}\right)$ are all changeless because its production conditions are changeless in a relatively short period.

Thus, at the given price $p$ of the pollution emission, the total of the pollution is $q=\sum_{i=1}^{n} g_{i}\left(q_{i}\right)$, where $q_{i}$, the response to $p$, is determined by the Equation (6). So the optimal price $p$ of the pollution emission is determined by the following equation:

$$
\begin{aligned}
0=\frac{\partial F}{\partial p}= & \sum_{i=1}^{n}\left(p_{i} \frac{\partial q_{i}}{\partial p}-\frac{\partial c_{i}}{\partial q_{i}} \frac{\partial q_{i}}{\partial p}\right)+p \sum_{i=1}^{n} \frac{\partial g_{i}}{\partial q_{i}} \frac{\partial q_{i}}{\partial p} \\
& -\sum_{i=1}^{n} \frac{\partial C}{\partial g_{i}} \frac{\partial g_{i}}{\partial q_{i}} \frac{\partial q_{i}}{\partial p}
\end{aligned}
$$

The optimal price $p$ can be obtained by solving the Equation (7) with the Equation (6), and then the optimal quantities of production $q_{i}$ is computed according to the Equation (6).

\section{Experiment}

In this section, we will illustrative a simple example to demonstrate the feasibility of our model.

Example 4.1. There are two firms to produce different production and emit the same pollution while the government chooses the price $p$ of the pollution emission. Supposing the two firms' quantity of the production are $q_{1}$ and $q_{2}$ and the prices of the productions are $p_{1}=10$ and $p_{2}=8$, respectively. Then, the firms' production conditions are assumed as follows: $g_{1}\left(q_{1}\right)=$ $2 q_{1}^{2}, \quad g_{2}\left(q_{2}\right)=5 q_{2}, \quad c_{1}\left(q_{1}\right)=3 q_{1}, \quad c_{2}\left(q_{2}\right)=q_{2}^{3}$. The cost function of abating the pollution is $C(q)=1000-2 q$, where $q=g_{1}\left(q_{1}\right)+g_{2}\left(q_{2}\right)$.

According to the assumption in the example (4.1), we can easily get the two firms' profit function formulated as follows:

$$
\begin{aligned}
& F_{1}\left(p, q_{1}\right)=p_{1} q_{1}-p g_{1}\left(q_{1}\right)-c_{1}\left(q_{1}\right)=10 q_{1}-2 p q_{1}^{2}-3 q_{1}, \\
& F_{2}\left(p, q_{2}\right)=p_{2} q_{2}-p g_{2}\left(q_{2}\right)-c_{2}\left(q_{2}\right)=8 q_{2}-5 p q_{2}-q_{2}^{3} .
\end{aligned}
$$

According to the Equation (6), at the given price $p$ of the pollution emission, the firms' optimal quantities of the production are determined by the following equations: $10-4 p q_{1}-3=0$ and $8-5 p-3 q_{2}{ }^{2}=0$. Thus, we have

$$
q_{1}=\frac{7}{4 p}
$$

and

$$
q_{2}=\frac{\sqrt{8-5 p}}{3}
$$


which show that the firms' optimal quantities of the production are involved with the price $p$ of the pollution emission, and increase when $p$ decreases. This accords with the real situations. So, the total of the pollution is $q=2 q_{1}{ }^{2}+5 q_{2}=\frac{1}{8 p^{2}}+\frac{5 \sqrt{8-5 p}}{3}$. And the government's objective is formulated as follows:

$$
\begin{aligned}
F(p, q)= & \sum_{i=1}^{2}\left(p_{i} q_{i}-c_{i}\left(q_{i}\right)\right)+p\left(\sum_{i=1}^{2} g_{i}\left(q_{i}\right)\right) \\
& -C\left(\sum_{i=1}^{2} g_{i}\left(q_{i}\right)\right) \\
= & \left(10 q_{1}-3 q_{1}\right)+\left(8 q_{2}-q_{2}^{3}\right)+p\left(2 q_{1}^{2}+5 q_{2}\right) \\
& -\left[1000-2\left(2 q_{1}^{2}+5 q_{2}\right)\right]
\end{aligned}
$$

According to the Equation (7), the optimal price $p$ is determined by the following equation:

$$
0=\frac{\partial F(p, q)}{\partial p} .
$$

Thus, the optimal price $p=0.9280$ is obtained by solving the Equation (10) with the Equations (8) and (9). Following, the optimal quantities $q_{1}=1.886$ and $q_{2}=0.611$ of the two firms' are obtained by the Equations (8) and (9).

From the simple example, we aim to reveal how the government (or the social government) chooses the optimal price of the pollution emission to maximize the social profits by considering the firms' response to the price, and how the firms determine the optimal quantity of the production at the given price to maximize their profits.

\section{Conclusions and Future Work}

In this paper a bilevel programming problem is proposed to determine the optimal price of the pollution emission, which is a novel way to discuss this problem. And an example is solved to illustrate the feasibility of the model, which can provide some consultations for the decision-makers. In the future, there are more researches to do, such as considering that there are more than one kind of production and pollution emissions and so on, so that more real problems are solved to abate the environmental pollution.

\section{Acknowledgements}

The authors would like to thank the anonymous editors and reviewers for their useful comments and suggestions. And the work is supported by the Social Science Foundation of Ministry of Education (No. 10YJC630233) and Hubei Province Key Laboratory of Systems Science in
Metallurgical Process (Wuhan University of Science and Technology) (No. B201003).

\section{References}

[1] Y. G. Zhu, L. Wang, Z. J. Wang, et al., "China Steps up Its Efforts in Research and Development to Combat Environmental Pollution,” Environmental Pollution, Vol. 147, No. 2, 2007, pp. 301-302. doi:10.1016/j.envpol.2006.10.001

[2] H. D. Kan, W. Huang, B. H. Chen, et al., "Impact of Outdoor Air Pollution on Cardiovascular Health in Mainland China”, CVD Prevention and Control, Vol. 4, No. 1, 2009, pp. 71-78.

[3] S. Managi and S. Kaneko, "Environmental Performance and Returns to Pollution Abatement in China," Ecological Economics, Vol. 68, No. 6, 2009, pp.1643-1651. doi:10.1016/j.ecolecon.2008.04.005

[4] H. F. Cheng and Y. N. Hu, "Lead (Pb) Isotopic Fingerprinting and Its Applications in Lead Pollution Studies in China: A Review,” Environmental Pollution, Vol. 158, No. 5, 2010, pp. 1134-1146. doi:10.1016/j.envpol.2009.12.028

[5] D. D. Cao, G. B. Jiang, Q. F. Zhou, et al., "Organotin Pollution in China: An Overview of the Current State and Potential Health Risk,” Journal of Environmental Management, Vol. 90, No. 1, 2009, pp. 16-24.

doi:10.1016/j.jenvman.2008.06.007

[6] J. H. Dales, "Pollution Properly and Price,” Toronto University Press, Toronto, 1968.

[7] United States Environmental Protection Agency (USEPA), Office of Water, “A Summary of U.S. Effluent Trading and Offset Projects, US,” Environmental Pro- tection Agency, Washington DC, 1999.

[8] E. Woerdman, "Implementing the Kyoto Protocol: Why JI and CDM Show More Promise than International Emissions Trading,” Energy Policy, Vol. 28, No. 1, 2000, pp. 29-38. doi:10.1016/S0301-4215(99)00094-4

[9] M. A. Amouzegar and K. Moshirvaziri, "Determining Optimal Pollution Control Policies: An Application of Bilevel Programming," European Journal of Operational Research, Vol. 119, No. 1, 1999, pp. 100-120. doi:10.1016/S0377-2217(98)00336-1

[10] M. A. Amouzegar and S. E. Jacobsen, “A Decision Support System for Regional Hazardous Waste Management Alternatives," Journal of Applied Mathematics and Decision Sciences, Vol. 2, No. 1, 1998, pp. 23-50. doi:10.1155/S1173912698000029

[11] X. J. Wang and S. Y. Feng, "The Optimality Theory of Bilevel System,” The Science Press, Cape Town, 1995.

[12] Z. Hu, C. Fu and X. Wang, "Property Rights Disposition and Management of Water Resources,” The Science Press, Cape Town, 2003.

[13] J. Bracken and J. M. McGill, "Mathematical Programs with Optimization Problems in the Constraints," Operations Research, Vol. 21, No. 1, 1973, pp. 37-44. doi:10.1287/opre.21.1.37

[14] H. V. Stackelberg, "The Theory of the Market Economy," 
Oxford University Press, Oxford, 1952.

[15] J. F. Bard, "Practical Bilevel Optimization: Algorithms and Applications,” Kluwer Academic Publishers, Dordrecht, 1998.

[16] S. Dempe, “Annotated Bibliography on Bilevel Programming and Mathematical Programs with Equilibrium Constraints,” Optimization, Vol. 52, No. 3, 2003, pp. 333-359. doi:10.1080/0233193031000149894

[17] B. P. Colson, P. Marcotte and G. Savard, "Bilevel Programming: A Survey,” A Quarterly Journal of Operations Research, Vol. 3, No. 2, 2005, pp.87-107.

[18] G. M. Wang, Z. P. Wan and X. J. Wang, "Bibliography on Bilevel Programming," Advances in Mathematics, Vol. 36, No. 5, 2007, pp. 513-529.

[19] J. F. Bard, "Some Properties of the Bilevel Linear Programming," Journal of Optimization Theory and Applications, Vol. 68, No. 2, 1991, pp. 371-378. doi:10.1007/BF00941574

[20] L. Vicente, G. Savard and J. Judice, "Descent Approaches for Quadratic Bilevel Programming," Journal of Optimization Theory and Applications, Vol. 81, No. 2, 1994, pp.
379-399. doi:10.1007/BF02191670

[21] G. Z. Ruan, F. M. Yang and S. Y. Wang, “A Simplex Algorithm to Solve Bilevel Linear Price Control Problem,” Systems Engineering Theory and Practice, Vol. 16, No. 12, 1996, pp. 38-43.

[22] C. X. Teng, Z. H. Li and L. Li, "Basic Properties and Continuity of the Solution Sets of Price Control Problem," Systems Engineering Theory and Practice, Vol. 17, No. 2, 1997, pp. 45-49.

[23] H. Y. Liu and S. Y. Liu, "A Note on Bilevel Linear Price Control Problem," Systems Engineering Theory and Practice, Vol. 19, No. 4, 1999, pp. 141-143.

[24] J. P. Dussault, P. Marcotte, S. Roch and G. Savard, “A Smoothing Heuristic for a Bilevel Pricing Problem," European Journal of Operational Research, Vol. 174, No. 3, 2006, pp.1396-1413. doi:10.1016/j.ejor.2004.07.076

[25] Y. B. Lv, T. Hu and Z. P. Wan, "A Penalty Function Method for Solving Weak Price Control Problem," Applied Mathematics and Computation, Vol. 186, No. 2, 2007, pp. 1520-1525. doi:10.1016/j.amc.2006.07.151 